\title{
Desde mi experiencia de escritor
}

\author{
JOAN MARI IRIGOIEN \\ Escritor
}

Cuenta mi madre que, faltando unos días para que yo naciera, di media voltereta en su interior; vino el ginecólogo —el doctor Arrillaga--, quien sabía de las aficiones literarias de mi padre, me volvió a colocar en el claustro materno como Dios manda, lo ciñó estrechamente con una faja, y le dijo: "Ahora sí, nacerá como es debido", pero llegó la hora de nacer, y nací con los pies por delante, completamente al revés. Cuando el padre vio que venía al mundo de aquella manera tan poco ortodoxa, pensó: "Este niño será futbolista"; el doctor Arrillaga no pensó ni dijo nada, estando como estaba tan perplejo y asombrado... pero cuando comprobó que los dolores de parto de mi madre habían menguado, le dijo a mi padre: "Oye, Román, este chico parece que tiene madera de escritor... pero de escritor surrealista"; mi madre no sabía qué pudiera ser el surrealismo, pero, como otras muchas veces, comprendiendo lo incomprensible de forma intuitiva, dijo a los dos hombres que tenía enfrente: "Haya que se tuerce, no hay quien la enderece". Los tres tenían razón.

Por haber nacido contra las más elementales reglas no sé si de la decencia pero sí de la medicina, estuve a punto de fallecer ( menudo favor que hubiese hecho a los que, por orden del profesor, están tratando de leer, impotentes, Poliedroaren hostoak: La tierra y el viento, en versión castellana!), pero cuando me llevaron a la ventana de la habitación a que me aireara, vi el cielo infinito allá arriba, sentí la caricia del viento en mis mejillas... y, recuperando mi aliento, decidí que aquélla no era hora de morir.

Por tanto, ahí tenéis ya dos de los ejes sobre los que he construido mi mundo literario: la muerte y la necesidad de espacios infinitos, en donde poder respirar.

De ahí en adelante, más allá de tribulaciones y penas, recuerdo una infancia muy feliz, en Alza, mi pueblo, correteando siempre por los prados, en busca de grillos y de mariposas, o pescando bermejuelas en el río, cuando no jugando al fútbol o a la pelota en el frontón. 
Mi padre era el médico del pueblo, y fue una persona clave en mi vida, que influyó de manera definitiva tanto en la formación de mi personalidad como en la decisión que en su momento tomé, cara a abrirme un camino en el territorio de las letras. Cuando terminaba su prácticamente interminable trabajo -interminable, sí, porque, a parte de estar sujeto día y noche a las necesidades sanitarias de los vecinos, solía pasar las consultas a domicilio, en nuestra propia casa, con aquellos aglomeramientos y aquellas colas sin fin en tiempos de gripe o de epidemia_-; cuando terminaba su trabajo, decía; cada vez que disponía de un rato libre, siempre me lo encontraba leyendo, ya fuera un libro o una revista, cualquier cosa. Sabía muchos poemas de memoria, poemas y párrafos enteros de los clásicos españoles: de Lope y de Calderón, de Fray Luis de León y de san Juan de la Cruz; o también de Cervantes... lo cual no es de extrañar, pues había leído unas veinte veces el Quijote. Mi padre también escribió algunos poemas: testigo de ellos puede ser el que tiene por título Nik zer ez eman zer ez egin ("iQué no daría yo, qué no haría...!"), y que aparece en la antología del padre Onaindia Mila olerki eder ("Mil magníficos poemas"). También tradujo del inglés una fábula de Oscar Wilde, Gizandi berekoia ("El gigante egoísta"). De entre los escritores vascos, era a Lizardi a quien más estimaba y admiraba. Recuerdo que, posteriormente, cuando empecé a garabatear mis primeros poemas, mi padre siempre me sonreía. Y su sonrisa era bella, iluminada por una mirada azul. A pesar de que él era médico, lo conocí siempre falto de salud. Quizá sea por ello que recuerde siempre su sonrisa, y es que no hay sonrisa más bella que aquella que germina en tierras del dolor: dolor que mi padre, por otra parte, sobrellevó desde su fe en la otra vida, pues, siendo católico practicante, creía en el otro mundo y en la eternidad.

¿Qué os voy a contar yo de la eternidad? Recuerdo aquellos funerales de mi infancia, cuando la música del órgano de la iglesia se me metía hasta el tuétano de los huesos; aquellos cirios encendidos por cuyas llamas decían que respiraban las almas de los difuntos; las multicolores vidrieras que en aquellos tiempos tenían los ventanales de la iglesia y que más tarde el párroco - un ciego y fanático cura, de cuyo nombre prefiero no acordarme - las hizo desaparecer; el incienso y el perfume que despedían las rosas del altar; aquellas palabras en latín que no entendía pero que me maravillaban y embrujaban... o puedo recordar, asimismo, los bosques y arroyos de mi infancia, en los que la eternidad no era un simple y puro sueño, sino que constituía y era la misma realidad, viva y... casi única realidad, en aquellas circunstancias, de entre las mil realidades posibles.

Puede que de aquella fe de mi padre (que no se limitaba a un cumplimiento tan sólo de lo ritual sino a una puesta en práctica de sus creencias, incluido el perdón a sus enemigos en tiempos de guerra y que lo plasmó en un soneto) y de aquellas tan intensas vivencias de mi infancia, nazca mi curiosidad e interés por todo lo que atañe a la metafísica, sin que ello implique que haya dejado de lado, ni mucho menos, la física, pues soy, al fin y al cabo, aunque no lo parez$\mathrm{ca}$, ingeniero... aunque tampoco estoy muy seguro de ello, pues todavía no tengo en manos el título que lo acredite, y no porque no acabara la carrera, sino porque todavía no he ido a recogerlo. 
Otra de las referencias de mi infancia es la Biblia. Cuando íbamos a la catequesis, el mismo párroco, del que antes os he hablado y de cuyo nombre ahora sí quiero acordarme - se llamaba don Félix - nos mostraba unos grandes carteles, llenos de figuras y de colorido, que manifestaban o reflejaban escenas de las Escrituras, y que en aquellos tiempos sin televisión y sin dibujos animados eran para nosotros motivo de asombro... y eran también como ventanas que nos llevaban a exóticas tierras y exóticos nombres, y es entonces cuando hice mi primer viaje - sí al menos con mi imaginación- a aquellos mágicos desiertos de Egipto y de Israel, en donde una lluvia de maná podía convertirse en el pan nuestro de cada día, o el cayado de Aarón en una serpiente.

En estos tiempos de pragmatismo hay quien dice que tengo en mi forma de ser un componente romántico, que ahora yo no voy a negar. Es más, creo que en mi concepción poliédrica del ser humano, en la que más adelante volveré a insistir, esa cara me enriquece, y creo que su fuente hay que buscarla en aquellos momentos felices de mi niñez; también es posible que se deba a que mi padre se llamara Román, y ya sabéis, de tal palo tal astilla.

Al lado de mi padre, recuerdo a mi madre, y la recuerdo como la mujer más bella - $\tan$ fermosa ella como la vaquera de la Finojosa, que diría el marqués-, allá en mi infancia. Y hoy en día, en su vejez - tiene 92 años, camino de 93 - , sigue siendo una mujer bella y adorable, más que antes si cabe, porque el tiempo de su alma es un tiempo sin arrugas. Hace mes y medio tuvo una fractura de cadera y, al mes después de la operación, ya podía valerse, como antes, por su propio bastón, para poder caminar de aquí allá. Hablando así de mi madre, los sicólogos y los siquiatras, y la ciencia, en definitiva, calificarían mi estado como de complejo de Edipo, que, como todos los complejos - los que realmente se tienen y los que uno se inventa o los que a uno le inventan-, son como una acusación, pero cuando la ciencia empieza a nombrar lo bello, ya se sabe... Espero que, de todos modos, no me lleven a la cárcel por semejante acusación, que algún sesudo juez podría tipificar como pertenencia o colaboración con banda edípica, esperemos que no.

Mi madre nació en un caserío —que, en su tiempo, fue también molinode un barrio (Sallobente) de Elgoibar. Era, por tanto, campesina, por lo que no es de extrañar el que haya aprendido de ella mil refranes y otros tantos cuentos e historias, basados en la tradición mítica y oral de nuestro pueblo. Aunque, como he dicho, era campesina por los cuatro costados, le encantaba oír y escuchar las lecturas que mi padre hacía en familia, aún cuando a veces no entendiera, mientras ella se dedicaba a las faenas de la casa, y así aprendí con ella que no hay siempre que entender de literatura - y sobre todo de poesía - para poder gozar de ella, ya que la literatura puede convertirse, de vez en cuando, más allá de todo conocimiento, en música y embrujo. Por ello, si a veces me consuela y me alegra el comprobar que los profesores de literatura se dediquen, en su labor de enseñanza, a comentar textos de diversos autores, y a profundizar en el estudio de sus obras, tomando como parámetros de estudio los distintos espacios y tiempos, así como los diferentes puntos de vista y estilos, o acciones y persona- 
jes; por otra parte, siento como un pequeño temor o cierta desconfianza, ya que la demasiada insistencia en los valores teóricos y estructurales de las obras puede impedir la lectura fresca de ellas, libres de prejuicios. Y esos dos planos o esas dos realidades conviven, de hecho, en mí, y así soy, por un lado, un lector hipercrítico, neurótico y pedante, sensible $\longrightarrow$ mejor, enfermizo- al menor detalle; y soy, por el otro - sobre todo en mis lecturas veraniegas, a la orilla de algún riachuelo de montaña--, un lector mucho más primitivo e ingenuo, capaz de creer que las palabras pueden ser como piedras de pedernal, que al contacto de las unas con las otras pueden producir destellos y chispas que nos encandilen. Mi madre veía y ve esas chispas, y es por ello, quizá, que siga creyendo, al igual que mi padre, en la eternidad, y es así que, a pesar de que mi padre muriera hace años, siga hablando mi madre todos los días con él... hola, qué tal estás, Román, cómo te va por esos mundo sin mí... Y hasta hubo un tiempo en que llevaba en su bolsa las Rimas de Gustavo Adolfo Bécquer, y no era raro verle recitar a ella misma alguna de aquellos poemillas, qué es poesía dices mientras clavas tu pupila en mi pupila azul, como si fueran una oración.

Para completar este cuadro, digamos que en tiempos de mi padre y mi madre estaba muy mal visto que una campesina se casara con todo un señor médico, pero, sobre todos los obstáculos y dificultades, ni uno ni otro cegaron en su empeño, por lo que, tras largos años de noviazgo —en los que debemos incluir los años de la guerra y los de encarcelamiento de mi padre, por vasco y separatista-, se casaron en el año 1940. Fruto de su matrimonio fueron los cinco hijos que tuvieron, entre los que yo soy el más joven.

Alguien me puede preguntar que qué hago yo aquí contando la vida de mis padres, pero supongo que he venido aquí a hablaros de mi obra, y mi obra no se puede entender sin tomar en consideración aquel mundo heredado de mis padres: era un mundo firme y sólido, casi sin grietas, y a pesar de que con el tiempo ha ido agrietándose aquí y allí, difícilmente puedo olvidarlo... y es que, además, no quiero olvidarlo.

El primer poema - Carta a los reyes magos- lo escribí a los once años, cuando iba al colegio de los corazonistas de Mundaiz de San Sebastián para aprender el bachiller: era un romance, supongo que malísimo, como poema mágico-monárquico que era, pero no recuerdo mucho más. Estaba allí de capellán un cura que también era poeta y escribía en euskara, Ignacio Goikoetxea "Gaztelu", quien, fuera de las horas lectivas, organizó unas clases de euskara, a las que asistía yo junto a otros compañeros, y en las que aprendí canciones que con el tiempo calarían en lo más hondo de mí: Hator hator mutil etxera. Itsasoa laino dago Baionako barraraino...

Más o menos por aquel tiempo, pasando por la plaza de mi pueblo, vi a una muchacha que hacía punto en el portal, y yo no sé qué me pasó que el corazón me dio un vuelco: fue así como se me abrió otra puerta, la puerta del amor, que ya en lo sucesivo no podría olvidar tanto en mi vida como en mis escritos.

También por aquella época le regalaron a una de mis hermanas un tocadiscos el día de su cumpleaños, y pude descubrir así el mundo de la música clá- 
sica: Beethoven, Mozart, Haendel, Bach, Verdi, Guridi, etc. Y fue en los imprevistos y esplendorosos arco iris que surgían de las obras maestras de aquellos músicos en donde vi por primera vez posarse a las aves del paraíso, que, remontando después el vuelo, dibujaban en la bóveda celeste aquellas sinfonías llenas de sueños y de color.

Y, mientras seguía estudiando en Mundaiz, abrí mi corazón a nuevas palabras y a nuevos idiomas, que de una forma u otra me impresionaron - subrayaré entre éstos el lenguaje matemático, tan aparentemente perfecto y sin tacha-... y, al poco, conocí a Rubén Darío, inclitas razas ubérrimas sangre de Hispania fecunda, y fue tal la impresión que me hizo, que decidí escribir un poema a su estilo, pero para entonces ya sabía yo de dónde era y dónde vivía, y es por ello que lo intitulé Oda a Euskal Herria, y, tomando la pluma, escribí: Rústico pueblo viril... Como acertadamente habéis pensado tampoco aquel poema pasó a la historia de la literatura, menos aún al libro de oro de la literatura feminista, ya que en su último congreso, según las referencias que tengo, ni lo mencionaron.

He dicho que "para entonces ya sabía yo de dónde era". También he dicho que mi padre era nacionalista y que por ello lo encarcelaron. Uniendo las dos ideas, alguien puede pensar que fue mi padre quien a base de arengas y soflamas diarias me adoctrinó. Pues, no. Fue el silencio de mi padre el que me habló. Y fue su tristeza. Y fue aquel detalle de levantarse de la silla y apagar la radio, cuando, tras los partes informativos, comenzaban a emitir el himno de los vencedores de la guerra, como si al apagar la radio recuperara la dignidad perdida. Y fueron aquellos libros enterrados por mi madre en una huerta cercana, de puro temor. Y nada más.

Pero, antes de continuar, quizá pueda resumir en un poema entresacado de mi libro Denborak ez zuen nora ("El tiempo no tenía adónde") todo aquel mundo de mi infancia:

\section{JARDINES PERDIDOS}

“... sin otra luz y guía / sino la que en el corazón ardía" S. JUAN DE LA CRUZ)

La colorida polifonía de aquellas inmarcesibles rosas de tu hogar, cuando para ti la eternidad era, sin más, flor de cada día.

O las palabras que acunaron tu infancia

en el origen de las cenizas:

los cuentos de la maga molinera: cuentos de brujas y de veleros; y la caricia de aquella voz de ojos azules: paisajes derramados en

poemas de silencio.

Asimismo,

el reloj de pared que la sombra perezosa del sol hacía avanzar; 
o arroyos de trigo, ya sin agua, que si bien cerraban todo un mundo al mismo tiempo abrían otro en el pan recién fermentado de cada día.

Y las trenzas de aquella muchacha, donde cada día se posaban, juguetonas, dos verdes mariposas, mientras tu corazón vivía saltando

de rosa en rosa, de una a otra eternidad.

Puedes recordar también los cuatro cirios en torno a aquel primer difunto, luces abiertas al otro mundo, que disolvían los cuatro puntos cardinales del féretro.

$\mathrm{Y}$ aquellos olores, cálidos, penetrantes, bíblicos perfumes que desde oasis lejanos traían los caballos del viento en carruajes de fuego, sándalo e incienso.

$\mathrm{Y}$, pues crees que puede volver a suceder aquello que una vez partirás de nuevo hacia aquellos jardines de la eternidad, aunque cansancio y herrumbre cubren hoy tu corazón.

En sexto de bachiller, organizó el colegio una excursión a Madrid, de una semana de duración, y de aquel viaje lo que más recuerdo es aquella salida que hicimos a Toledo, en donde me quedé maravillado con El entierro del conde de Orgaz de El Greco: allí estaba, entonces también, presente la muerte, rodeada de aquellas figuras que, en su verticalidad, parecían no sé si trascenderla o demorarla. Posteriormente, uno de mis hermanos, Manuel, que también es poeta - además de despistado-, comenzó a pintar, y con su ayuda pude profundizar en el conocimiento del mundo de la pintura, visitando durante un tiempo exposiciones, no sólo en San Sebastián, sino también en Barcelona y Madrid.

En los años siguientes, no paré: comencé a estudiar la carrera de ingeniería; jugué a fútbol en el Sanse, que era por entonces el equipo filial de la Real Sociedad; empecé mi alfabetización en euskara, por mi cuenta y riesgo, por supuesto — creo que leí por aquella época el Joanak joan de Etxaide y algunos poemas de Lizardi-; di clases nocturnas de euskara en mi pueblo... Junto a estos datos no podría olvidar este otro, y es que, en aquellos tiempos de Franco, nuevas corrientes de pensamiento vinieron a nuestro encuentro desde el ancho mundo, nuevas ideologías - nuevas para nosotros, aunque de suyo eran ya bastante viejas: marxismo, anarquismo, etc.- , y, con la irrupción de aque- 
llos vientos, temblaron las columnas sobre las que se erigía todo nuestro mundo, como si todo él fuera de papel: quisiera subrayar en este aspecto, el varapalo que recibió, como consecuencia de ello, toda nuestra educación sexual, basada en aquella doctrina de la iglesia y en aquella estrecha moral tan agobiante y tan asfixiante, que no sabía más que de sublimaciones y de complejos de culpabilidad; y mientras iban marchitándose en nuestro corazón aquellas flores de la sublimación, una nueva palabra floreció en nuestros labios: libertad; con el tiempo aprendí que también la libertad tiene sus espejismos, así como la sublimación puede tener sus aspectos positivos e igualmente gratificantes, pero esas son otras historias; otro aspecto que quisiera recalcar y que, tanto en mi historia personal como literaria, es fundamental, es la destrucción de aquel paraíso de mi infancia: la destrucción, sí, de mi pueblo, por todas aquellas aves de rapiña - gobernantes, constructores y especuladores-, que no tuvieron ningún reparo en convertir aquel paisaje vivo en un monumento a la muerte, hecho de cemento sobre cemento, de la forma más antiestética... y, jes que hay tantas formas de matar! Como botón de muestra os diría que, si alguna vez venís a San Sebastián, os paseéis por la zona de Larratxo, y lo comprobéis con vuestros propios ojos: allá yace sepultado, entre feísimas torres impersonales, aquel riachuelo que tan feliz me hizo en la niñez.

$\mathrm{Y}$, así, cuando tenía unos veinte años comencé a escribir mis primeros poemas en euskara: Hutsetik esperantzara (De la nada a la esperanza). Cuando acabé el libro, lo presenté al Ciudad de Irún: el libro resultó, para mi sorpresa, ganador. Sobra decir que aquel premio me alegró muchísimo y que me reafirmó en la idea de continuar escribiendo. Por ello, aunque uno, con el paso del tiempo, puede llegar a ser más crítico y escéptico respecto a los premios literarios - más de ciertos premios que de otros--, nunca podremos negarles el valor que puedan tener a nivel personal, tanto en lo que supone de reconocimiento y ánimo para los vencedores - sobre todo si son noveles-, como de compensación económica.

Para entender aquellos poemas, hay que tener en cuenta el tiempo en que fueron desarrollados: son poemas escritos con el corazón, a golpe de sentimiento, sencillos, y sin una mayor preparación teórica, pues, estando como estaba tan atareado entre estudios y entrenamientos, poco tiempo me quedaba para tales reflexiones. Es cierto que hoy no hubiese escrito dichos poemas, pero también es cierto que tenemos que aprender a asumir nuestro propio pasado, tanto desde la ternura como desde la ironía... y, además, no es malo recordar que, en estos tiempos en que a uno le parece que en cualquier momento se le va a secar el corazón, hubo otro tiempo en que éste fue manantial de sentimientos puros y generosos; por ello, desde esta perspectiva, hay poemas que todavía, afortunadamente, me emocionan, como pueden ser aquellos dos que dediqué, uno a mi padre, y el otro a una mujer de la vida de Caracas, que con su lección me mostró que era precisamente la vida la mejor universidad, y que no había más remedio que matricularse en ella, si uno quería aprender algo.

$Y$ es que, tras acabar la carrera, tuve la oportunidad de ir a Venezuela, en principio con la intención de adentrarme en la Amazonía venezolana en apoyo 
de un proyecto indígena, para quedarme finalmente en Caracas dando clases de física y matemáticas, como consecuencia, por una parte, de que el proyecto se pospuso, y de que tuve serios problemas con los mosquitos, por otra. Fue aquel año, por lo demás, un año loco e inolvidable.

A la vuelta de las Américas, leí dos libros: Leturiaren egunkari ezkutua de Txillardegi, y Haur besoetakoa de Mirande, y, tras leer aquellos libros, llegué al convencimiento de que el euskara, como cualquier otra lengua, podía servir de instrumento para escribir los libros más hermosos, aunque para ello era totalmente necesario el prepararse cada vez más y más, leer e investigar. Y un día pensé (téngase en cuenta que unos tres años antes se habían decidido las bases de lo que hoy en día es el euskara batua o euskara unificado): ¿Por qué no escribir una novela, mientras voy profundizando en los conocimientos del euskara?

En mi estancia en Venezuela leí muchísimo y, aunque antes de cruzar el charco, había ya leído Cien años de soledad, el contacto con aquellas gentes me predispuso aún más hacia el realismo mágico, que en el fondo no era sino una traslación del cuento infantil al mundo de los adultos, y, bajo su influencia, me puse a escribir mi primera novela: Oilarraren promesa (La promesa del gallo).

Yo ya sabía que la realidad no era blanca o negra y que, entre ambos polos, existían todos los demás colores, pero también es cierto que la realidad es muchas veces terrible... y fue terrible para nosotros en aquellos tiempos de Franco, con aquella falta de libertad y con la destrucción de todo aquel entorno de mi pueblo, en donde el cemento fue la primera forma de terrorismo que yo conocí... Y así fue como me salió la novela, cruda y apocalíptica, dentro de lo que puede denominarse una literatura de compromiso. He citado una palabra: compromiso, y, al hilo de esta cuestión, quisiera hacer un pequeño paréntesis. Y es que hay una opinión bastante extendida entre algunos escritores, que defienden la tesis de que cuando se mezcla la literatura con la política, siempre es en perjuicio de aquélla. Y yo no estoy, en principio, de acuerdo: menos todavía en nuestro pueblo, en donde la política ha sido y es - tanto para bien como para mal-el motor de muchos de nuestros sueños e impulsora de no pocos de nuestros amores y odios. Y, ¿no se escriben las novelas $\longrightarrow$ muchas de las novelas- para expresar tanto los amores y odios de las personas así como sus sueños? Por tanto, desde mi opinión, la cuestión no es si hay que introducir o no temas políticos en la novela, sino cómo se introducen en el contexto general de ella.

Volviendo sobre lo mismo, no quisiera dejar de lado la situación actual de mi país. Fue ayer precisamente cuando tuvo lugar la sentencia condenatoria de la mesa nacional de HB, y estoy indignado. No porque esté de acuerdo con la estrategia de la coalición, que a lo largo de la reforma me ha parecido poco inteligente, sino porque el PP, cada vez más en una línea neofranquista - testigo de ello son los documentos internos filtrados últimamente-, parece ser que nos quiere imponer una pax hispana, a la que muchos vascos nos vamos a 
resistir. Hay que echar más imaginación al asunto. En ese sentido, me parece encomiable la labor que iniciaron ELA y LAB, en busca de nuevos parámetros que puedan reconducir la realidad vasca por caminos nuevos y distintos, pero me temo que este veredicto va a tensar aún más las cuerdas, y no sé, no sé... Porque cuando el dolor es muy grande, se ciega el corazón y se ciegan los ojos del corazón, y ya no importa lo que pueda pasar, como no sea el dar rienda suelta a las frustaciones y sentimientos inmediatos, derivados de tan penosa situación. Y ya uno no mira al mañana sino al hoy. Y el desahogo de hoy es el desastre del mañana.

Llegados aquí, ¿como dejar de lado el mundo del euskara? Hace unos cuatro años estuve en Verines (Asturias), en unas jomadas organizadas creo que por el Ministerio de Cultura, en la que nos reunimos veinticinco escritores y críticos del estado, y extraigo un párrafo de lo que allá dije: "(...) Con tal motivo podría (...) reprobar ese artículo de la constitución por la que un ciudadano de Euskal Herria está obligado a saber el español y no el euskara y que no acabo de entender, como no sea que quieran convertirnos en ciudadanos de segunda categoría. (...) Resumiendo les diré que aspiro a ser un vasco normal, que quiere vivir en su idioma de una forma normal, y que, dentro de los límites geográficos de Euskal Herria, no esté pendiente de si aquél lo entiende o no. Espero que estas palabras no se interpreten como un desprecio mío a la cultura en lengua española, pues en mi mundo espiritual cuento como a amigos del alma a egregios escritores como Cervantes y san Juan de la Cruz, o más modernamente a prosistas como el ya fallecido J. Fernández Santos y Delibes, o a poetas como Colinas, Brines, Valente y tantos más, a alguno de los cuales hasta he tenido el gusto de conocer personalmente". Y, tras la cita, digo que hay cosas que no se pueden tolerar. Hace un par de semanas supimos de la sentencia dictada por algún juez a un abogado, con multa de un millón de pesetas, por negarse éste a la defensa de su cliente, quien, siendo euskaldun, reclamaba su derecho a ser entendido en su lengua, sin mediación de intérpretes. Y otros dos abogados fueron condenados, por la misma razón, con sendas multas de 300.000 pesetas. Y ahora yo les pido que hagan un ejercicio de imaginación y piensen qué hubiera sucedido si se hubiese hecho lo mismo, pero al revés, con un castellanoparlante. Seguro que muchos periódicos lo hubiesen traído a sus titulares. Y no digamos lo que se hubiese comentado en las tertulias radiofónicas, como sucedió cuando lo de la ñ, en los teclados. Aquí, sin embargo, no ha pasado nada. Todos somos demócratas, y tan contentos.

Pero tampoco he venido aquí a echar un mitin, y quisiera volver sobre aquel tiempo de mi juventud en que parecía que estábamos a las puertas de un nuevo mundo, más justo y más humano. Eran tiempos también en que los escritores en euskara queríamos llevar nuestras creaciones literarias - lejos de las sacristías - por nuevos derroteros. Pero no todos los caminos que abocaban en la modernidad eran iguales y no era raro comprobar que el que emprendía uno de ellos denostara de todos los demás. Y, ¡cuántas críticas injustas se hicieron, con tal motivo, en su momento! Al uno, porque utilizaba un estilo recargado que lo hacía elitista; al otro, porque utilizaba un tono épico, que parecía no 
tener ningún sentido en los tiempos que corrían, sobre todo después de Kafka; a éste, porque no se "mojaba", y a aquél, porque había escrito una novela de ambiente rural, y aquello era como volver al tiempo de las cavernas, en un mundo donde lo urbano era lo que primaba. Eran siempre planteamientos excluyentes, al estilo de "lo uno o lo otro, esto o aquello". Yo, afortunadamente, no caí - por una vez- en aquellos errores, y siempre pensé que las vanguardias ya habían dado todo lo que tenían que dar de sí y que vivíamos en un momento ecléctico, y que, por tanto, todos los caminos y todos los "ismos" (surrealismo, hiperrealismo, existencialismo, etc.) eran válidos si se utilizaban inteligentemente, y que cada uno debía decidir qué ruta o qué rutas iba a tomar en cada momento, y con qué se iba a quedar y qué iba a dejar. Y que a aquellos caminos lo único que les podíamos añadir era nuestro propio aliento, al estilo de Aurelio Arteta, aquel gran pintor vasco, que consiguió dar a su cubismo - inspirado, por otra parte, en Picasso, Braque y Juan Gris - un acento tan personal.

Sí, eran tiempos en que se invocaba la modernidad, casi como si fuera una palabra mágica. Después vino la postmodernidad. Y habrá alguien que todavía diga que no es posible lo moderno o lo postmoderno fuera del plástico y las computadoras. Yo, sin embargo, creo que lo moderno no son los materiales ni lo temas -que también lo pueden ser, por supuesto-, sino el tratamiento de ellos. Y que tan moderna puede ser una novela situada en el siglo II, como Las memorias de Adriano de Marguerite Yourcenar, que cualquier otra que tenga por protagonista a un extraterrestre. Es posible que a alguno de ustedes les extrañe que les cuente cosas tan obvias, pero ésas eran nuestras discusiones.

Recapitulando lo hasta ahora dicho, me doy cuenta de que, con motivo de aquella primera novela que escribí - Oilarraren promesa-, me he extendido quizá demasiado y, cambiando, por tanto, de tema, digamos que, tras escribir aquella novela, volví a Venezuela, donde hice un año más, ahora en Maracaibo, en una escuela de magisterio, al arrimo de otro escritor - Antonio Pérez Esclarín-, aragonés él, buen hombre y brillante orador, y que aquel año que pasé allí fue otro año loco y feliz, entre las clases, las noches, y los viajes sin fin, tanto a los distintos rincones de Venezuela, como a otros países: Colombia, Ecuador y Perú...

Y al volver, escribí mi segunda novela, Poliedroaren hostoak (traducida al castellano bajo el título de La tierra y el viento, aunque la traducción literal hubiera sido Las hojas del poliedro, pero que no me gustó, y publicada este mismo año en la editorial Hiru, una editorial marginal). Quise darle a aquella novela la estructura de un volcán que estallara en mil pedazos, porque yo mismo era, probablemente, aquel volcán. Es cierto que edificios, templos y demás monumentos surgen muchas veces con una belleza inusual bajo las leyes del equilibrio, pero no es menos cierto que también hay espectáculos bellos basados en el desequilibrio de las fuerzas, y que tal es la explosión de un volcán... siempre que a uno no le pille debajo, claro está. Es una novela que narra las aventuras y desventuras de dos sagas familiares, desde las guerras carlistas hasta los días en que se instaura en España la democracia. Como bien 
apuntó Karlos Otegi en su crítica del libro, la novela desarrolla una interpretación simbólica de la realidad vasca desde sus fundamentos, partiendo de la identificación de los carlistas con la tierra, como principio y símbolo de la tradición, la fe, las costumbres y el inmovilismo, y de los liberales, identificados con el aire, como imagen emblemática de la libertad y del movimiento, de la ciencia y de la capacidad de inventiva; continuando, dichos principios, en perpetua lucha dialéctica, hacia posteriores generaciones, cada vez más complejas en su forma de ser - ahora ya son unos mitad de tierra y mitad de aire-, a través de la guerra civil y del franquismo; y culminando en el último eslabón de la cadena, que no es más que el correspondiente al mismo escritor, que en el fondo es el resultado de todo el proceso dinámico precedente, y que en cada célula suya sentirá una diferente composición de tierra y aire, en una síntesis compleja, y que acabará diciendo que "mil yoes vivían dentro de mí", y esos yoes son las personas o los personajes que le van hablando desde las hojas del árbol genealógico, que van, por otra parte, configurando en el espacio una especie de poliedro, con sus distintas caras, que atrapan finalmente al escritor en su interior y que acaban por definirlo.

Quería, pues, en esta novela, analizar la complejidad del hombre moderno, como si uno estuviera hecho de diferentes pedazos correspondientes a distintos yoes, y, para plasmar esa fractura interna, me pareció conveniente escribir los capítulos con técnicas, registros y ritmos diversos; intercalando reflexiones filosófico-metafísicas, diálogos poéticos y monólogos, investigaciones policiales, juegos de palabras, exotismos, saltos de unos espacios a otros y de unos tiempos a otros, etc.

Sabía que una obra de este tipo corría el riesgo de que resultara con un montón de defectos, pero entonces prefería - y hoy, a veces, también - una obra imperfecta pero con fuerza y energía, que una obra pefecta pero sin corazón, y así salió como salió aquel libro, sobre el que debo de añadir que, al igual que Arteta se basó en el cubismo de Braque, Picasso y Juan Gris, para edificar su mundo tan personal, así cimenté yo mi libro sobre las experiencias literarias de Gabriel García Márquez y de Juan Rulfo... mientras afirmo, de paso, que pocos escritores hay que me hayan impactado tanto como el genio mejicano, creador, prácticamente, de un único libro, y de aquel Comala inolvidable.

$\mathrm{Y}$ recuerdo aquel día en que escuchando unos madrigales del siglo XIV, estando yo sobre mi escritorio, decidí cerrar los ojos, y dejé volar a mi imaginación. Y volé y volé, hasta que llegué a una puerta de hierro, guarnecida por dos cipreses, centinelas del más allá. Llamé a la puerta, y nadie vino. Grité, pero en vano. Hasta que decidí yo mismo abrir la puerta. Al abrirla, oí un largo chirrido, como si la muerte me estuviera hablando desde la herrumbre de la puerta.

Di un paso adelante, dos, y tres... y vi una losa: "Aquí yace Juan Rulfo". Comprendí que estaba en Comala.

$\mathrm{Y}$ yo mismo no sabía ya si estaba vivo o muerto.

_Juan, ¿estás ahí? 
—Sí - me respondió y, sin darme tiempo a hablar, continuó:- Ya sé a qué has venido...

— ¿Sí...? ¿Cómo puede ser eso, si ni yo mismo lo sé...?

-Tú ya sabes lo que dijo el filósofo: "Sólo sé que nada sé", y el que nada sabe lo sabe todo.

-Entonces no es tu caso, porque al saber eso, ya sabes algo...

-Sí, tienes razón... Y porque creía que sabía algo, dejé hablar a Pedro Páramo, ¿te acuerdas?

-Sí.

-Y la gente decía por mí: “¿Ese sí que sabe!” ¿Te acuerdas también...?

¡Cómo no me voy a acordar!

Agarrándome de la mano me llevó a su biblioteca.

-Pero lo que la gente nunca supo fue que aquel libro que resumía mi obra no era más que el preludio de este otro que...

- ¿Has escrito, pues, otro libro? Comala!

- ¡Ay, tú también como ellos... y eso que has conseguido entrar en

- No te entiendo...

-El primer libro fue como la senda que me encaminó al segundo, al definitivo, a aquél en que definitivamente lo supe todo, porque ya nada había que aprender. ¿Quieres que te lo lea?

-Sí.

Juan Rulfo llevó la mano a uno de los estantes... y fue entonces cuando me di cuenta de que los estantes estaban vacíos. Después, hizo aquel gesto, como si fuera a tomar un libro con su mano.

- ¿Ves este libro?

-No, yo no veo nada...

— ¿Cómo vas a verlo, si todo él, si todas sus páginas están hechas de silencio...? -y abrió el libro.

Y sucedió entonces aquel instante de silencio total, en el que pasado, presente y futuro fueron una misma sustancia.

Fue un sólo instante, sí... y fue en aquel instante que me pareció que yo también lo sabía todo.

Escribí, después, otra novela: Udazkenaren balkoitik (Desde el balcón del otoño), una novela mucho más convencional, que trataba - y trata- del mundo de nuestros padres y de nuestro propia generación, porque creí oportu- 
no que ya era hora de que nosotros contáramos nuestras propias historias, aburrido ya de que casi siempre fueran otros los que las contaran y, más de una vez, las tergiversaran, como ha solido suceder - y todavía sucede- frecuentemente. Creí, en un momento dado, que el proceso de elaboración sería sencillo, pues aquellas historias que tenía en mente me resultaban cercanas; al contrario, el proceso fue difícil y complicado, hasta el punto de que puedo afirmar que ha sido esta novela la que más me ha costado, como si lo próximo fuera una dificultad añadida. Y es que es fácil decir que hay que tratar con ternura a la gente que uno ha querido: sin embargo, tan cercana está la ternura de lo cursi, que no sé...

Junto a esta novela y, casi desgajada de ella, escribí un largo cuento o una breve novela - iqué más da...! - para jóvenes —eso de "para jóvenes" o "para adultos" son formas de hablar, ustedes me entienden-: Bakarneren gaztelua (El castillo de Bakarne), un libro del que, en su tiempo, quedé satisfecho, si no hubiera sido porque me lo publicaron con cantidad de faltas. Afortunadamente, lo van a reeditar dentro de poco, y podré quitarme la espina...

Y, después, Babilonia, mi novela más exitosa, aunque para mí no la mejor (la mejor es siempre la última, es decir, la que uno está escribiendo, aunque luego no lo sea). Traducida, en su momento, al catalán, la envié hace unos meses a la editorial SM, de donde me comunicaron ayer mismo que les había gustado y que la iban a publicar en octubre del próximo año, dentro de la colección Acento. Es un libro de ambiente rural - y al mismo tiempo moderna, en su ejecución-, que cuenta la historia del caserío Babilonia, allá por las guerras carlistas, y es, asimismo, un libro de síntesis de mis anteriores experiencias: retomo de Oilarraren promesa el realismo mágico; de Poliedroaren hostoak, el lenguaje poético, para describir todo un mundo mítico y de creencias; y de Udazkenaren balkoitik, el estilo realista. Al contrario que en Poliedroaren hostoak, de estructura totalmente abierta, quise darle una forma firme y cerrada, circular, para lo que se me ocurrió contar la historia desde tres punto de vista, a modo de tres arcos de $120^{\circ}$, que completaban el círculo y se complementaban entre sí. Para describir el mundo mítico que aparece en las páginas de Babilonia, os recordaré una anécdota. Cuenta mi madre que, siendo ella niña, allá por los años de la primera guerra mundial más o menos, fue a la fuente a por agua, y que de repente oyó un ruido ensordecedor. Se dio la vuelta y una luz brillante la cegó. Y pensó entonces: "Es la señora de Amboto que me quiere llevar consigo". La señora de Amboto era la bruja de los alrededores que deambulaba de un lado para otro, surcando el cielo como un meteorito, cuando más le venía en gana. Pero la señora de Amboto no se llevó a mi madre, sencillamente, porque aquella luz no era de tal señora, sino del primer automóvil que por primera vez se adentró en el barrio de mi madre. Y yo, para describir aquel mundo, tenía que recuperar aquel punto de vista de mi madre, si es que quería hacer algo más o menos atractivo y fascinante: pero ustedes son los que tienen que decidir si aquello que me propuse lo conseguí, si es que alguna vez tienen la opción de leer el libro. Y, de paso, si es que para entonces no me ha llevado la señora de Amboto a mí mismo por los aires, me escriben dándome su impresión. 
Viene ahora Denborak ez zuen nora, un libro de poemas del que les he leído ya un poema, y del que pueden hacerse una idea sin más.

Después, Consummatum est, otra de mis novelas, en donde se cuentan dos historias paralelas - una que tiene por protagonista a un sádico fascista, vecino de Sotonuevo, un pueblo de España, y la otra que trata de la vida de una monja mística de origen alemán, cuyo padre es poseedor de un castillo en Sotonuevo- y que es, en definitiva, un canto al perdón. Creo, por decir algo, que el personaje de la monja es uno de los más elaborados y más logrados por mí, pero por ahora no hay ni traducción, ni edición en castellano, por consiguiente. Es posible que el próximo año nos decidamos a traducirla, a ver qué pasa...

Escribí luego un libro de poemas para un publico juvenil Metak eta kome$t a k$, en donde toco de todo un poco: fábulas, juegos de palabras, poemas breves al estilo de los haikús, etc.

El año pasado, publiqué otro par de libros: uno, dedicado también a un público juvenil, titulado Apaiz zaharraren gitarra (La guitarra del viejo cura), y cuenta las peripecias de un cura y de unos jóvenes que viven en un barrio marginal, que plantean sus luchas desde una perspectiva enteramente imaginativa y constructiva, un poco en la línea de las luchas llevadas a cabo por la coordinadora de Itoiz y no muy lejos de las proposiciones de un Gandhi sin descafeinar.

El otro libro Kalamidadeen liburua (El libro de las calamidades), es una novela también de crítica social, contada en clave caricaturesca y de humor, y en la que procuro reírme de casi todo, incluido de mí mismo, y que no tiene nada que ver con mis anteriores producciones, como no sea con La guitarra del viejo cura, que he citado anteriormente. Es, en suma, una pequeña y saludable gamberrada, a la que creo todos tenemos derecho de vez en cuando.

$\mathrm{Y}$ ahora voy a hacerme propaganda. Porque sólo faltaba eso, que un escritor venga a Madrid y no se haga propaganda. Ustedes no conocen mi obra, pero quizá tengan la oportunidad de conocerla. No quedarán defraudados. Compren, compren mis libros, que una de dos, o les van a gustar mucho, o se van a quedar dormidos. Si les gustan, con el placer de la lectura se sentirán recompensados. Si, al contrario, se quedan dormidos, piensen que han hecho la inversión de su vida. Pues, ¿no es acaso uno de los mayores problemas de hoy el stress y el insomnio? Muchos de ustedes son jóvenes, y no saben lo que es el insomnio. Pero, más adelante, lo sabrán. Es ley de vida. Y no sabrán qué hacer. E irán al sicólogo o al siquiatra, que ya por su primera consulta les cobrará cuatro veces el precio del libro. $Y$ les recetará unas pastillas, que con la nueva ley del medicamentazo les supondrá un gasto adicional. Y les citará a una nueva consulta. A otra más, y otra más... Y difícilmente van a solucionar su problema. Compren, compren mis libros, ¡cómprenlos ya!, que terminarán ahorrando. Y ustedes me lo agradecerán.

Finalizo, hablando de mis próximos proyectos. Hace unos tres o cuatro años que comencé a escribir algunos poemas breves, que espero constituyan el 
próximo año un libro. Se titulará, creo, Kiribilak (Espirales). Va a ser un libro más de silencios que de palabras, al que creo voy a incluir al final una serie de liras, que, si en la literatura española cuentan con una rica tradición, en la literatura vasca no. $Y$ es que la lira, sobre todo en manos de grandes poetas como Fray Luis de León o san Juan de la Cruz, es una composición que siempre me ha seducido, tanto por el ritmo como por la musicalidad.

Pero para entender un poco el espíritu del libro, voy a traer aquí una cita de aquel artículo que escribí para aquel encuentro que tuvimos en Verines, y que llevaba por título El territorio de las letras. Decía, o dice así, dicha cita: "Otro punto transcendental es el del tiempo y el de la muerte, porque al fin y al cabo, ¿no será ese territorio como un baluarte que construimos piedra a piedra y palabra a palabra, contra tanta desolación y tanta ruina? Pues sabiendo que la vida es humo y que el humo casi ya no es, soñamos con la solidez de la piedra, que es lo mismo que decir que soñamos con ese tiempo sin tiempo, que no puede venirnos sino de nuestra propia energía interior, capaz de hacernos sentir las "cosas creadas como una red que cubre el mundo y cuyos hilos se comunican con los planetas y las estrellas", en palabras de Gérard de Nerval. ¿Será por ello que dentro de ese poliedro que somos - que al ser poliedro es cerrado y es noche: noche oscura del alma-, nos esforzamos en mantener una de las caras abiertas, para que a modo de claraboya podamos vernos en ese espejo más amplio que es el más allá, a la espera que definitivamente se haga la luz? Sé que en estas palabras late el espíritu de románticos y místicos, con su deseo de unión con el Uno o con el Todo, sueño que en mis días más felices, pese a todo, sigo compartiendo, lejos del cansancio y del desamor".

Vaya, como ejemplo, este par de poemillas, elegidos al azar:

No decir nada,

para que la nada nos diga.

Camaleón,

espejo de las apariencias,

cuerpo cambiante de la palabra.

Y todo fue así hasta que,

tras los velos,

unos labios de ceniza me besaron.

¿Fue la rosa de tus cenizas la que me besó...?

El otro proyecto es una novela ambiciosa, ubicada, por ahora, a finales del siglo XVII, que me llevará su tiempo. Entretanto, algo más surgirá, si no es que la señora de Amboto... Pero eso ya lo he dicho antes, y vamos a dejarlo ahí. Eskerrik asko, muchas gracias. 